\title{
FUZZY COPRAS METHOD FOR PERFORMANCE MEASUREMENT IN TOTAL PRODUCTIVE MAINTENANCE: A COMPARATIVE ANALYSIS
}

\author{
Ebru TURANOGLU BEKAR ${ }^{1}$, Mehmet CAKMAKCI ${ }^{2}$, \\ Cengiz KAHRAMAN ${ }^{3}$
}

\author{
${ }^{1}$ Graduate School of Natural and Applied Sciences, Dokuz Eylul University, \\ Tinaztepe Campus, 35160 Izmir, Turkey \\ ${ }^{2}$ Department of Industrial Engineering, Faculty of Engineering, \\ Dokuz Eylul University, 35397 Izmir, Turkey \\ ${ }^{3}$ Department of Industrial Engineering, Faculty of Engineering, \\ Istanbul Technical University, 34367 Istanbul, Turkey \\ E-mails: ${ }^{1}$ ebruturanoglu@gmail.com; ${ }^{2}$ mehmet.cakmakci@deu.edu.tr; \\ 3 kahramanc@itu.edu.tr (correspondingauthor)
}

Received 16 April 2016; accepted 13 June 2016

\begin{abstract}
Modern manufacturing firms should be supported by effective maintenance to become successful in their operations. One of the approaches for improving the performance of maintenance activities is to implement a total productive maintenance (TPM) strategy. Overall equipment effectiveness (OEE) is the key measure of TPM. According to the results of the literature review, the performance elements measured by the OEE tool are not sufficient to describe the effectiveness of TPM implementation. Hence, we aim at developing and evaluating new performance measures oriented towards the quantification of TPM implementation effectiveness under fuzzy environment. For the evaluation of each performance measure, at first, the nominal group technique has been used. Then to determine whether these performance measures are statistically significant, conjoint analysis based experimental design has been applied. In the second step, COmplex PRoportional ASsessment of alternatives with Grey relations (COPRAS-G) and the fuzzy COPRAS method has been developed to evaluate these performance measures in TPM. Proposed fuzzy COPRAS method gives the reassuring results of ranking newly developed performance measures in TPM.
\end{abstract}

Keywords: COPRAS-G, performance measurement, new performance measures, total productive maintenance, conjoint analysis, fuzzy COPRAS.

JEL Classification: C6.

\section{Introduction}

TPM is a new concept for maintenance that better optimizes the equipment effectiveness, minimizes breakdowns and encourages operators to autonomous maintenance for day-to-day activities involving total workforce (Andersson 2015). TPM aims to improve equipment effectiveness during the lifetime of the equipment. 
Nakajima (1988) initiated TPM concept in the 1980s, which brought measurable metric named OEE for measuring productivity of individual equipment in a factory. It explains and measures losses of significant sides of manufacturing specifically availability, performance, and quality rate.

OEE approach has been starting to be widely used as an important quantitative metric for measurement of productivity in manufacturing operations (Huang et al. 2003). The use of OEE varies from one industry to another, and it is tailored to fit to comply with industries' specific requirements.

According to the literature review on performance evaluation in TPM, OEE metric has widely been used as an important performance measure, but it is not adequate to define the effectiveness of TPM. Jeon et al. (2011) also suggested measuring the performance of TPM in terms of efficiency. This has caused to a requirement for a thoroughly described performance measurement system for TPM which is capable of considering different significant elements of productivity in a manufacturing process. Therefore, in this study new performance measures having an impact on TPM are proposed and proposed performance measures are evaluated under fuzzy environment.

The innovative side of this study is to develop new performance measures in TPM and also to evaluate these performance measures developed fuzzy COPRAS method in which no defuzzification step used for avoiding information loss. In the proposed fuzzy COPRAS method, all calculations are performed in accordance with fuzzy arithmetic.

In this study, it is aimed to develop new performance measures impact on TPM and using a multi criteria decision making method based on the concepts of COPRAS under fuzzy environment. The rest of the paper is organized as follows. Section 1 explains the problem and literature review. Section 2 introduces the literature review and the fundamentals of COPRAS-G method. In Sections 3 and 4, an application of COPRAS$\mathrm{G}$ and proposed fuzzy COPRAS method for evaluation of developed new performance measures in TPM are presented. In the last section, results and conclusion are given.

\section{Problem of the definition and literature review on TPM}

Many investigations have been underlined from a review of literature and case studies for implementing TPM successfully in manufacturing organizations. For example, Davis (1996) brings a crucial adding to the perceiving of implementation issues connected to the TPM program. Attri et al. (2014) presents a graph theoretic approach to evaluate the innumerable barriers in real life cases during TPM implementation. Chlebus et al. (2015) also focus the important issues when implementing TPM approach. Rodrigues and Hatakeyama (2006) claimed that the achievement of TPM implementation is closely related to the management of employees. The important thing is to find out key metrics for the assessment of performance indicators of the program. Piehnicki et al. (2015) investigate priority of critical success factors for implementing TPM properly.

Generally, TPM can be defined with regards to quantitative metric that is OEE which at the end can be taken into account a combination of the operation maintenance, equipment management and available resources (Hansen 2002). It determines and measures 
losses of important aspects of manufacturing specifically availability, performance, and quality rate. Calculated OEE for one manufacturing line can be used for comparison of the line performance across the factory, therefore highlights any weak line performance and indicates where to focus TPM resources. This is a widely accepted metric as a quantitative tool for measurement of productivity in manufacturing operations (Dal et al. 2000). Even the OEE is a popular quantitative tool and has been widely used in the literature; its usage is limited for the productivity measurement of single equipment (Huang et al. 2003).

Scott and Pisa (1998) remarked that although the benefits in OEE are valuable, they are not sufficient since no machine is separated from others. Their remark is that manufacturing processes involves complex interacts among process tools, materials, machines, people, departments, companies, and processes. Therefore it is important to focus on performance of the whole plant instead of performance of single equipment. Oechsner et al. 2003 also stated that the main goal is to obtain efficient integrated system not perfect single equipment.

A survey for literature of TPM using the electronic databases such as Emerald, Science Direct, Springer, ASME, and etc. gives 191 published papers (only titles). The results of this research are given in Table 1. According to Table 1, out of the total of 149 papers, 87 papers (near about 58.39 per cent of total articles) are of TPM implementation and case study types, 33 papers (near about 22.15 per cent of total articles) are of empirical research on TPM, 20 papers (near about 13.42 per cent of total articles) are of model and simulation type studies and 9 papers (near about 6.04 per cent of total articles) are of literature type study.

Table 1. Classification of research papers on TPM

\begin{tabular}{|c|c|c|c|c|}
\hline Years & $\begin{array}{l}\text { Empirical } \\
\text { research }\end{array}$ & $\begin{array}{l}\text { Literature } \\
\text { review }\end{array}$ & $\begin{array}{l}\text { Implementation } \\
\text { and case study }\end{array}$ & $\begin{array}{c}\text { Modelling } \\
\text { and simulation }\end{array}$ \\
\hline 1994 and below & 9 & & 15 & 2 \\
\hline $1995-2000$ & 9 & 1 & 14 & 4 \\
\hline $2001-2002$ & 2 & & 6 & 1 \\
\hline $2003-2004$ & 3 & & 5 & 1 \\
\hline 2005 & & & 3 & 1 \\
\hline 2006 & 1 & 1 & 6 & 2 \\
\hline 2007 & & & 1 & \\
\hline 2008 & 1 & 2 & 6 & 1 \\
\hline 2009 & 2 & & 2 & \\
\hline 2010 & 1 & & 6 & 1 \\
\hline 2011 & 2 & 1 & 7 & 3 \\
\hline 2012 & 1 & 1 & 11 & 1 \\
\hline 2013 & 1 & 1 & 1 & 1 \\
\hline 2014 & 1 & 2 & 2 & 1 \\
\hline 2015 & & & 2 & 1 \\
\hline
\end{tabular}


Based on the results of literature review, very little progress has been made related to the analysis of TPM effectiveness. It is concluded that analysing the TPM performance needs more future systematized applications focused at reinforcing theoretical frames and raising importance of the implementation of more practical approaches. Therefore, in this study new performance measures having an impact on TPM are developed. The proposed performance measures are evaluated under fuzzy environment. According to literature review and the best knowledge of the authors, this is the first study that employs proposed fuzzy COPRAS method to evaluate newly developed performance measures in TPM.

\section{Methodology}

TPM implementation and practicing is a cultural change and an organization wide activity. For this reason, measuring the effectiveness of TPM is ordered an organization wide program based on some factors having impact on TPM. The overall aim is to develop a standard methodology for measuring various improvements, resulting from TPM implementation. Proposed TPM effectiveness system can be divided into three phases: (i) the design of the new performance measures, (ii) the evaluation of the new performance measures, and (iii) the implementation and the use of the new performance measures to carry out analysis/reviewing.

The present findings show that there should be greater use of TPM than literature suggests as a performance improvement process and those improvements must be measured both subjectively and quantitatively. So there are a large number of conflicting tangible and intangible factors that should be considered in development of new performance measures. In this study, after developing new performance measures, it is aimed to handle the multi criteria decision making (MCDM) problems under uncertain information to evaluate the new performance measures.

Literature review indicates that recently developed MCDM methods such as COPRAS, ARAS, SWARA, MOORA, WASPAS and etc., and their modifications have been applied to solve different kinds of problems using fuzzy and grey number theory (Zavadskas et al. 2014). Liu and Zhang (2013) also proposed a novel method integrating entropy weight and an improved ELECTRE III method to select supplier in supply chains. Liu and $\mathrm{Wu}$ (2012) suggested a new model based on multi-granularity linguistic variables and VIKOR method for assessment of competency of human resources managers. Zhang et al. (2013) developed a new decision making analysis method based on grey relational projection. Liu and Teng $(2014,2015)$ presented extended TODIM method with the form of 2-dimension uncertain linguistic variables and the intuitionistic uncertain linguistic variables. In these methods, we apply COPRAS-G and improved fuzzy COPRAS methods for assessment of new performance measures in TPM. It possesses some advantages. For instance, it uses not certain, unclear information about the alternatives' criterion values stated in terms of intervals; it is more appropriate in real life applications; its calculations are not complex; it needs smaller samples not involved a typical distribution; and it is an effective method in taking care of discrete data. The overall structure of the study is shown in Figure 1. 


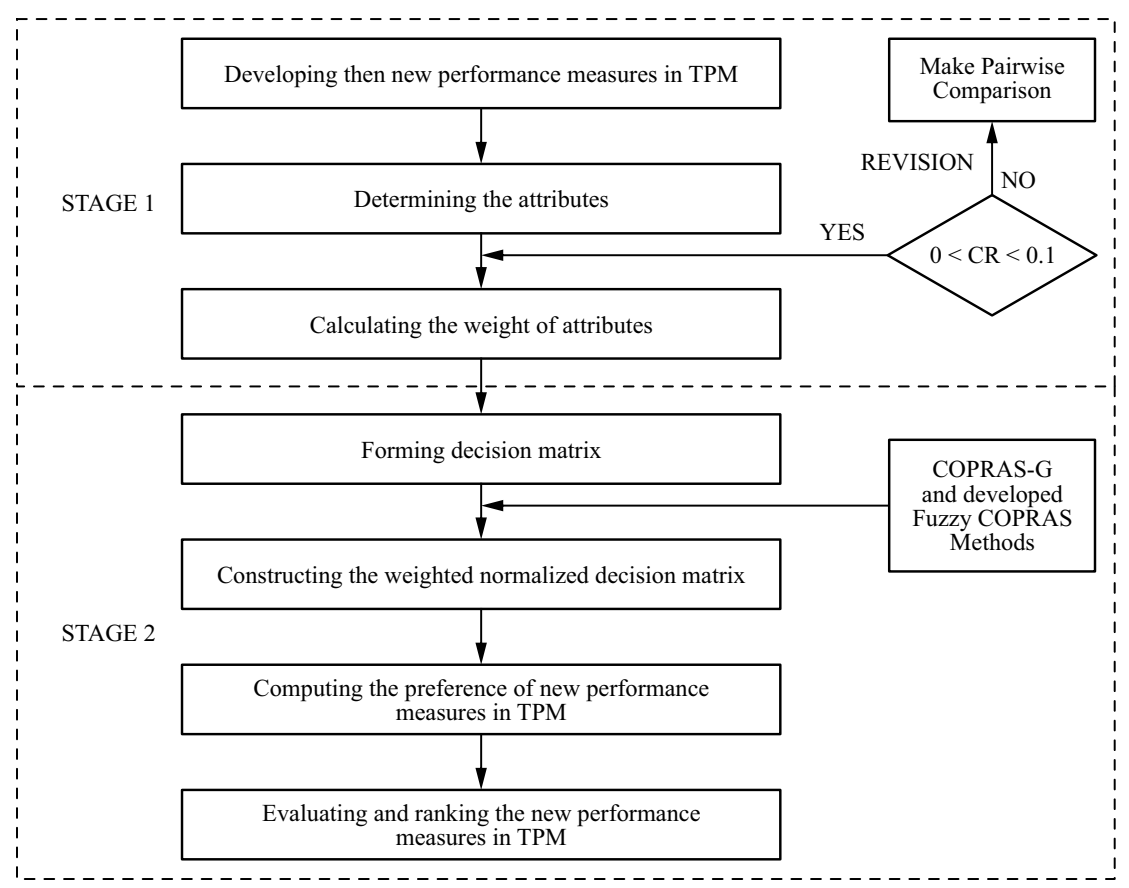

Fig. 1. The overall structure of the study

\subsection{Literature review on COPRAS-G method}

Multiple attributes decision aid provides several powerful and effective tools for confronting sorting problems (Kahraman et al. 2015; Mardani et al. 2015). The idea of COPRAS-G method is based on the real conditions of decision making and applications of the Grey systems theory (Zavadskas et al. 2014).

A literature review for COPRAS-G method using "Scopus" gives 149 published papers (all fields) among these, 35 papers mention COPRAS-G method in "article title, abstract, keywords". The papers mentioned COPRAS-G method in "article title, abstract, keywords" are surveyed by analysing the publishing frequencies with respect to years; the document type; the research areas; the most cited papers on COPRAS-G method, respectively shown as in Figures $2-4$ and Table 2.

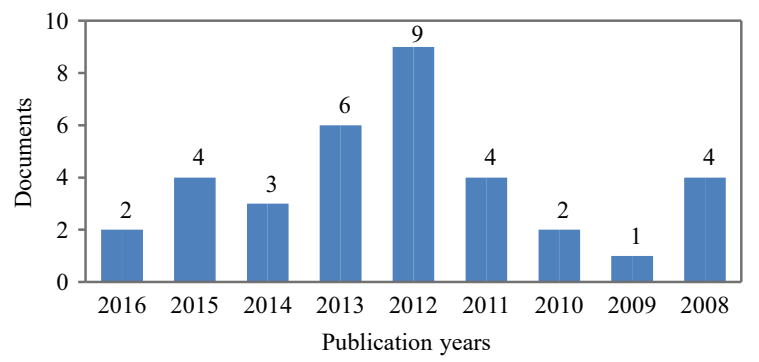

Fig. 2. Published papers using COPRAS-G method over years 


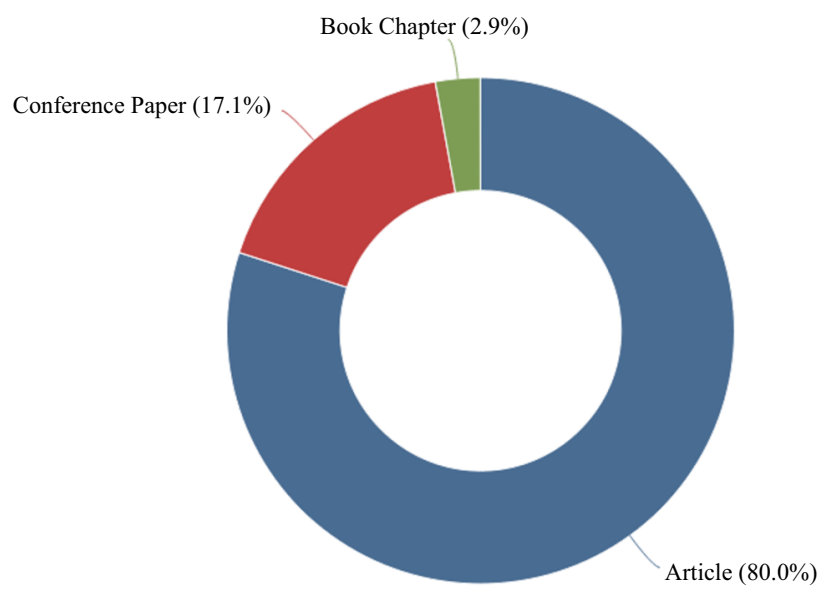

Fig. 3. The classification of published papers using COPRAS-G according to document types

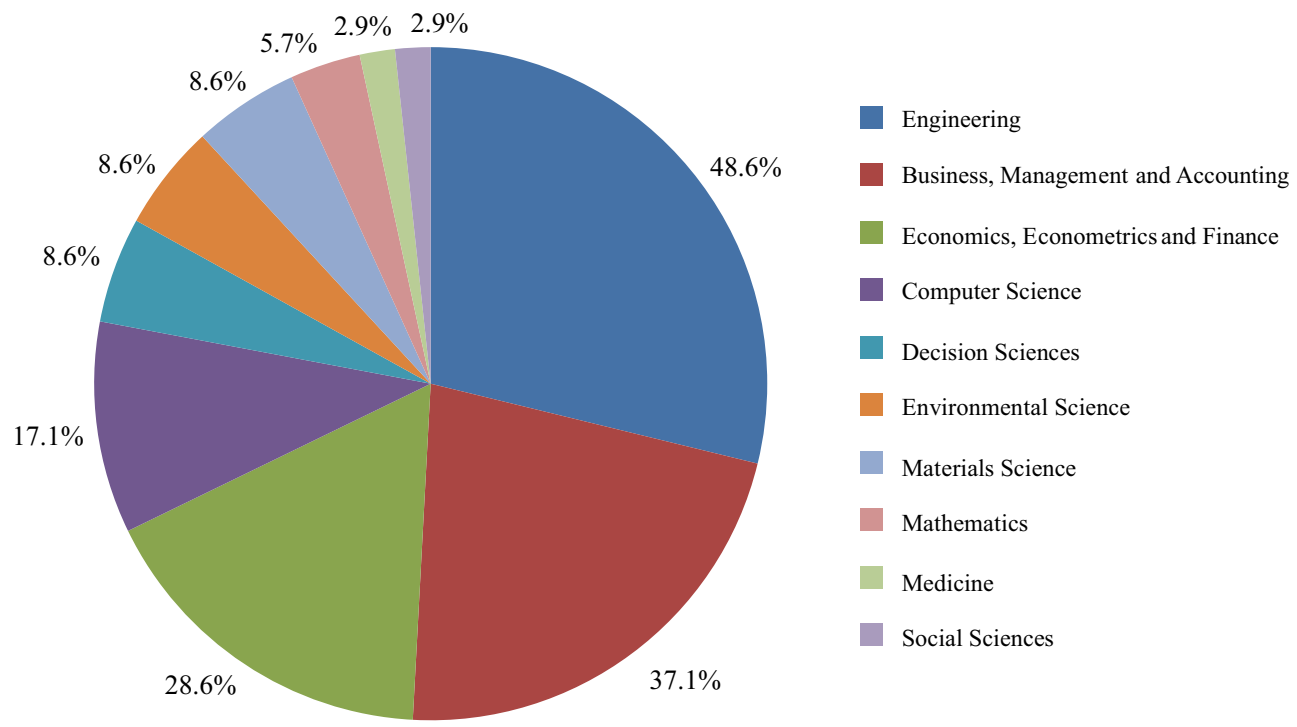

Fig. 4. Research areas of the examined papers using COPRAS-G

According to Figure 3, 28 papers using COPRAS-G are published as an article, 6 papers as a conference paper and 1 paper as a book chapter. The areas of Engineering, Business Management and Accounting, Economics, Econometrics and Finance are the most studied research fields on COPRAS-G shown in Figure 4.

In recent years, the COPRAS-G method and its hybrid modifications have been applied to the solution of complicated MCDM problems using fuzzy sets theory. Ecer (2015) proposed a hybrid model based on fuzzy AHP and COPRAS-G methods to evaluate the performance of internet banking branches. Ghorabaee et al. (2014) proposed multiple 


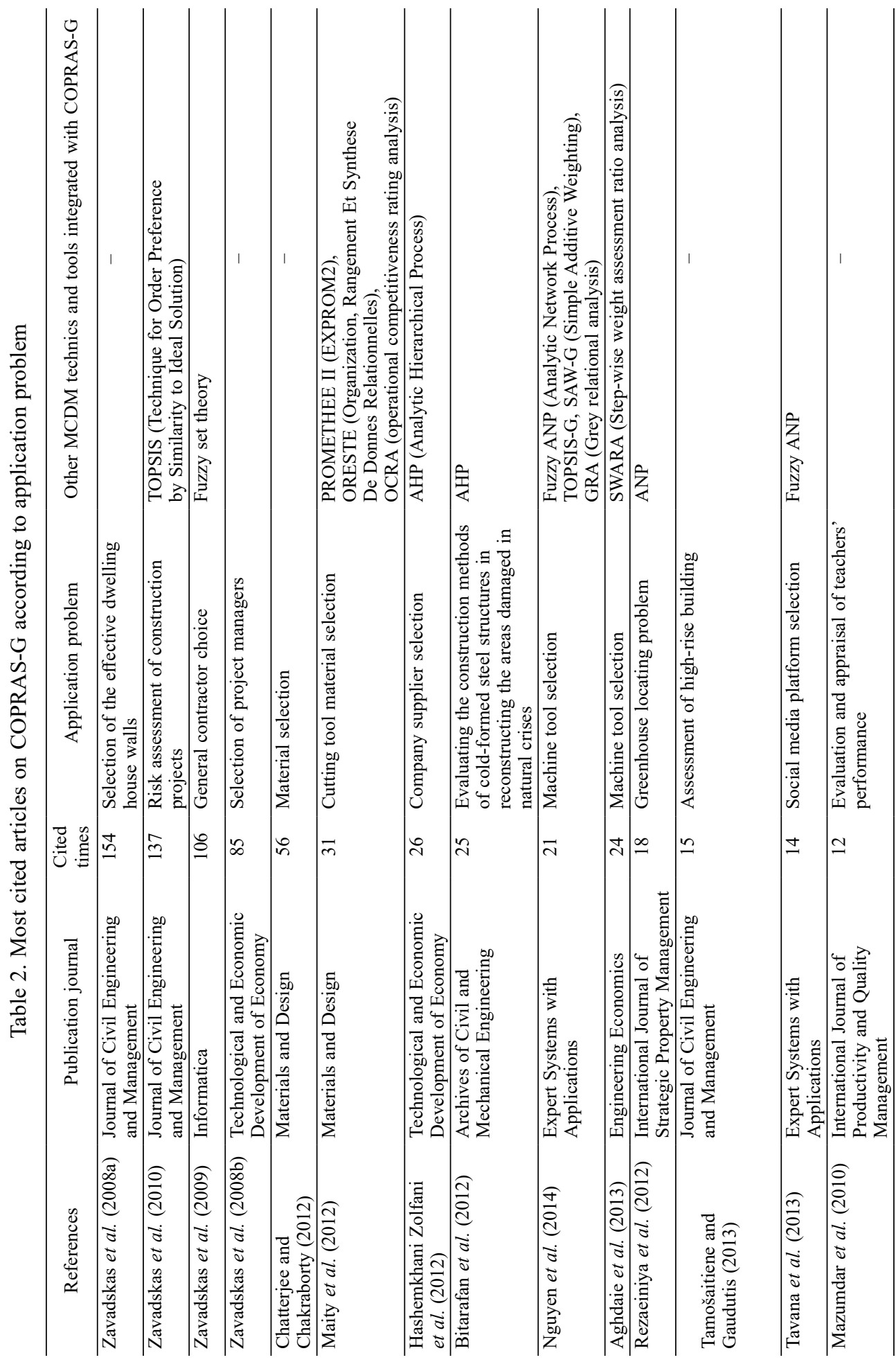


criteria group decision-making for supplier selection based on COPRAS method with interval type-2 fuzzy sets. Liou et al. (2016) presented a new hybrid COPRAS-G Multi attribute decision making (MADM) model for selecting suppliers in green supply chain management. Zavadskas and Antucheviciene (2007) were firstly suggested multiplecriteria complex proportional evaluation under fuzzy environment to assessment the rural building's regeneration alternatives. Yazdani et al. (2011) developed a risk based methodology for critical infrastructures using fuzzy COPRAS (COPRAS-F) extended of COPRAS method. Antucheviciene et al. (2012) applied TOPSIS-F, COPRAS-F and VIKOR-F to rank the redevelopment decisions of derelict buildings under fuzzy environment. Chatterjee and Bose (2012), Nguyen et al. (2015) and also Akhavan et al. (2015) studied different MCDM problems using COPRAS-F method. COPRAS method has also been handled by new extensions of fuzzy sets such as intuitionistic or hesitant fuzzy sets (Razavi Hajiagha et al. 2013; Bausys et al. 2015; Gitinavard et al. 2016).

\subsection{COPRAS-G methodology}

The COPRAS-G method employs a stepwise ordering and assessing procedure of the alternatives with respect to importance and utility degree based on the Grey systems theory. Zavadskas et al. (2008a, 2009) represented the basic notions of the COPRAS-G method include the following steps:

1. Selecting the set of the most important attributes, describing the alternatives.

2. Constructing the decision-making matrix $\otimes X$ :

$$
\begin{gathered}
\otimes X=\left[\begin{array}{ccc}
x_{11} & \ldots & \otimes x_{1 m} \\
\ldots & \ddots & \ldots \\
\otimes x_{n 1} & \ldots & \otimes x_{n m}
\end{array}\right] ; \\
=\left[\begin{array}{ccc}
{\left[w_{11} ; b_{11}\right]} & \ldots & {\left[w_{1 m} ; b_{1 m}\right]} \\
\ldots & \ddots & \ldots \\
{\left[w_{n 1} ; b_{n 1}\right]} & \ldots & {\left[w_{n m} ; b_{n m}\right.}
\end{array}\right], j=\overline{1, n} ; i=\overline{1, m},
\end{gathered}
$$

where: $\otimes x_{j i}$ is determined by $w_{j i}$ (the smallest value, the lower limit) and $b_{j i}$ (the biggest value, the upper limit).

3. Determining weights of the attributes $q_{i}$.

4. Normalizing the decision-making matrix $\otimes X$ :

$$
\begin{aligned}
& \overline{w_{j 1}}=\frac{w_{j i}}{\frac{1}{2}\left(\sum_{j=1}^{n} w_{j i}+\sum_{j=1}^{n} b_{j i}\right)}=\frac{2 w_{j i}}{\left(\sum_{j=1}^{n} w_{j i}+\sum_{j=1}^{n} b_{j i}\right)} ; \\
& \overline{b_{j 1}}=\frac{b_{j i}}{\frac{1}{2}\left(\sum_{j=1}^{n} w_{j i}+\sum_{j=1}^{n} b_{j i}\right)}=\frac{2 b_{j i}}{\left(\sum_{j=1}^{n} w_{j i}+\sum_{j=1}^{n} b_{j i}\right)}, \quad i=\overline{1, n} \text { and } j=\overline{1, m} .
\end{aligned}
$$

In Eq. (3), $w_{j i}$ is the lower value of the $i t h$ attribute in the alternative $j$ of the solution; $b_{j i}$ is the upper value of the attribute $i$ in the alternative $j$ of the solution; $m$ is the number 
of attributes; $n$ is the number of the alternatives compared. Then, the decision-making matrix is normalized by Eq. (4):

$$
\otimes \hat{X}=\left[\begin{array}{ccc}
\otimes \overline{x_{11}} & \ldots & \otimes \overline{x_{1 m}} \\
\ldots & \ddots & \ldots \\
\otimes \overline{x_{n 1}} & \ldots & \otimes \overline{x_{n m}}
\end{array}\right]=\left[\begin{array}{ccc}
{\left[\overline{w_{11} ; b_{11}}\right]} & \ldots & {\left[\overline{w_{1 m} ; b_{1 m}}\right.}
\end{array}\right], j=\overline{1, n ; i}=\overline{1, m}
$$

5. Calculating the weighted normalized decision-making matrix $\otimes \hat{X}$. The weighted normalized values $\otimes \hat{x}_{j i}$ are calculated as follows:

$$
\otimes \hat{x}_{j 1}=\otimes \hat{x}_{j 1} \cdot q_{i} ; \hat{w}_{j 1}=\bar{w}_{j 1} \cdot q_{i} ; \hat{b}_{j 1}=\bar{b}_{j 1} \cdot q_{i} .
$$

In Eq. (5), $q_{i}$ is the weight of the $i t h$ attribute. Then, the weighted normalized decisionmaking matrix is shown as follows:

$$
\otimes \hat{X}=\left[\begin{array}{ccc}
\otimes \hat{x}_{11} & \ldots & \otimes \hat{x}_{1 m} \\
\ldots & \ddots & \ldots \\
\otimes \hat{x}_{n 1} & \ldots & \otimes \hat{x}_{n m}
\end{array}\right]=\left[\begin{array}{ccc}
{\left[\hat{w}_{11} ; \hat{b}_{11}\right]} & \ldots & {\left[\hat{w}_{1 m} ; \hat{b}_{1 m}\right.} \\
\ldots & \ddots & \ldots \\
{\left[\hat{w}_{1 n} ; \hat{b}_{1 n}\right]} & \ldots & {\left[\hat{w}_{n m} ; \hat{b}_{n m}\right.}
\end{array}\right] .
$$

6. Calculating the sums $P_{j}$ of the attribute values, whose larger values are more preferable:

$$
P_{j}=\frac{1}{2} \sum_{i=1}^{k}\left(\hat{w}_{j 1}+\hat{b}_{j 1}\right)
$$

7. Calculating the sums $R_{j}$ of attribute values, whose smaller values are more preferable:

$$
R_{j}=\frac{1}{2} \sum_{i=k+1}^{m}\left(\hat{w}_{j 1}+\hat{b}_{j 1}\right), i=\overline{k, m} .
$$

8. Determining the minimal value of $R_{j}$ :

$$
R_{\min }=\min _{i} R_{j}, j=\overline{j, n} .
$$

9. Calculating the relative weight of each alternative $Q_{j}$ :

10. Determining the optimality criterion $K$ :

$$
Q_{j}=P_{j}+\frac{\sum_{j=1}^{n} R_{j}}{R_{j} \sum_{j=1}^{n} \frac{1}{R_{j}}}
$$

$$
K=\max _{j} Q_{j}, j=\overline{1, n} .
$$

11. Determining the priority of the project.

12. Calculating the utility degree of each alternative using $Q_{j}$ and $Q_{\max }$ which are the weight of projects obtained from Eq. (10):

$$
N_{j}=\frac{Q_{j}}{Q_{\max }} 100 \% \text {. }
$$




\section{COPRAS-G method for the evaluation of new performance measures in TPM}

In this study, an outline for defining different types of performance measures impact on for TPM is proposed, as shown in Table 3. This classification helps the decisionmaker to measure different factors impact on TPM so that attention should be provided to the appropriate factors. It also contributes a systematize method of quantifying asset effectiveness.

In this study, firstly it is illustrated that a framework for identifying different types of performance measures' impact on TPM and then these possible performance measures were analysed by decision makers. These decision makers work at operational, tactical and strategical levels in a company operating in the automotive industry. They determined the ranking of performance measures impact on TPM using the nominal group technique and then the twelve performance measures having scored higher than 15 were

Table 3. Factors affecting TPM (Braglia et al. 2009, Muchiri Pintelon 2008)

\begin{tabular}{|c|c|}
\hline Category & Factors \\
\hline \multirow[b]{2}{*}{ Operational related } & $\begin{array}{l}\text { Planned downtime } \\
\text { - Number of preventive maintenance } \\
\text { - Preventive maintenance time }\end{array}$ \\
\hline & $\begin{array}{l}\text { Unplanned down time } \\
\text { - Number of unplanned maintenance (equipment failures) } \\
\text { - Mean time between failure (MTBF) } \\
\text { - Mean time to repair (MTTR) (failure frequency) } \\
\text { - Set up (changeovers), adjustments } \\
\text { - Routine wear parts } \\
\text { - Minor stoppages \& idling } \\
\text { - Reduced speed } \\
\text { - Quality losses } \\
\text { - Reduced yield }\end{array}$ \\
\hline Business related & $\begin{array}{l}\text { - Stock control } \\
\text { - Spare parts inventories } \\
\text { - Internal logistic problems (storage, shipping) } \\
\text { - Organization problems \& labour unrest } \\
\text { - Environmental, Health \& safety problems } \\
\text { - Capital project }\end{array}$ \\
\hline External related & $\begin{array}{l}\text { Logistic problems } \\
\text { - Supplier failure } \\
\text { - Delivery time } \\
\text { - Utility shortage (gas, electricity or waters) } \\
\text { Environmental regulation } \\
\text { - Production quatos } \\
\text { Natural causes } \\
\text { - Weather conditions }\end{array}$ \\
\hline Others & $\begin{array}{l}\text { - Human factor } \\
\text { - Availability of maintenance personnel }\end{array}$ \\
\hline
\end{tabular}


selected. To determine whether these twelve performance measures are statistically significant, conjoint analysis has been performed that is a MCDM technique based on the experimental design. Then if we had used the full factorial design for conjoint analysis there would be 212 combinations because each performance measure has two levels. We should reduce the number of designs. For this reason, in this study Taguchi design methodology was used to reduce the number of designs. Then the conjoint analysis was performed by using Taguchi OA 16 table.

Part-worth was estimated based on the value placed on each level of the individual factor. The ANOVA results of conjoint analysis are displayed in Table 4:

Table 4. ANOVA results of conjoint analysis

\begin{tabular}{cccccc}
\hline Model & Sum of squares & df & Mean square & F & Sig. \\
\hline Regression & 333.250 & 12 & 27.771 & 12.343 & .031 \\
\hline Residual & 6.750 & 3 & 2.250 & & \\
\hline Total & 340.000 & 15 & & & \\
\hline
\end{tabular}

According to Table 4, the value of test statistic $\mathrm{F}$ is found 12.343. Also significance level $\alpha$ (Sig.) is found to be 0.031 , it is concluded that the proposed multiple regression model for the twelve performance measures impact on TPM are statistically significant. Finally the relative weights of these performance measures were calculated. Regarding to calculation, the performance measures that are number of unplanned maintenance and environmental and health \& safety problems have the highest relative weights with the values $16.19 \%$ and $15.24 \%$, respectively. Also the performance measures that are number of preventive maintenance and preventive maintenance time have the relative weights with the value 0 . That means these performance measures don't have the statistically significant impacts on TPM. Therefore these two performance measures are ignored after the COPRAS-G method is performed. In this study, the remaining ten performance measures are evaluated by COPRAS-G method under some attributes.

The set of attributes and initial values of attributes are determined on the basis of expert, normative and calculation methods. According to the literature investigation and expert's opinions, the committee finally adopted 6 criteria. The selected attributes for TPM performance measures assessment are as follows: $x_{1}$-specific (score) is clear and concentrated to keep away misunderstanding and it should contain measure suppositions and descriptions and be simply explained; $x_{2}$-measurable (score) can be quantified and resembled to other data; $x_{3}$-attainable (score) is achievable, rational, and reliable under the conditions expected; $x_{4}$-realistic (score) conforms to the organization's restrictions and is profitable; $x_{5}$-timely (score) is available within the time frame given; $x_{6}$-cost of measure (score) (Parida et al. 2005). The first five attributes are benefit attributes, while the last attribute is cost one. In order to establish the attribute weights pair wise comparison method has been carried out. The consistency index of pairwise comparisons of attributes is calculated and then it is found 0.0106 . It is less than 0.1 , so the preferences are deemed to be consistent. 
Table 5. Initial decision-making matrix with values of the attributes describing the compared alternatives in intervals

\begin{tabular}{lccc}
\hline \multicolumn{1}{c}{ Attributes } & Specific & Measurable & Attainable \\
\hline Optimization direction & MAX & MAX & MAX \\
\hline Attribute weight- $\mathrm{q}_{\mathrm{i}}$ & 0.0352 & 0.2329 & 0.3079 \\
\hline Performance measures & $\otimes x_{1}$ & $\otimes x_{2}$ & $\otimes x_{3}$ \\
\cline { 2 - 4 } & $w_{1} b_{1}$ & $w_{2} b_{2}$ & $w_{3} b_{3}$ \\
\hline Environmental, health \& safety problems & 5075 & 7585 & 7080 \\
\hline Organization problems \& labour unrest & 5580 & 5256 & 6276 \\
\hline Human factor & 6078 & 7585 & 7080 \\
\hline Availability of maintenance personnel & 7093 & 5462 & 5572 \\
\hline Quality losses & 8489 & 8090 & 7580 \\
\hline Reduced speed & 8489 & 7585 & 7080 \\
\hline MTBF & 8595 & 7888 & 6070 \\
\hline MTTR & 8595 & 7888 & 7080 \\
\hline Number of unplanned maintenance & 8095 & 8090 & 8085 \\
\hline Reduced yield & 8489 & 8090 & 8590 \\
\hline Attributes & Realistic & Timely & Cost of measure \\
\hline Optimization direction & MAX & MAX & MIN \\
\hline Attribute weight- $\mathrm{q}_{\mathrm{i}}$ & 0.2540 & 0.0506 & 0.1193 \\
\hline Performance measures & $\otimes x_{4}$ & $\otimes x_{5}$ & $\otimes x_{6}$ \\
\hline Environmental, health \& safety problems & $w_{4} b_{4}$ & $w_{5} b_{5}$ & $w_{6} b_{6}$ \\
\hline Organization problems \& labour unrest & 7580 & 6585 & 9080 \\
\hline Human factor & 7075 & 5781 & 5652 \\
\hline Availability of maintenance personnel & 7080 & 7078 & 5855 \\
\hline Quality losses & 8090 & 5993 & 6254 \\
\hline Reduced speed & 7585 & 6389 & 9080 \\
\hline MTBF & 7075 & 8085 & 8580 \\
\hline MTTR & 8090 & 808590 & 7060 \\
\hline Number of unplanned maintenance & 7585 & 8590 & 5550 \\
\hline Reduced yield & & 7060 \\
\hline
\end{tabular}

As long as the decision procedure, the decision maker team was demanded to fulfil the decision matrix by making the comparison of alternatives regarding with each of the attributes one by one. The decision matrix created on expert knowledge is formed in order to assess the new performance measures in TPM. Initial decision matrix with values of the attributes defining the compared alternatives in intervals and also the weights of attributes are given in Table 5. According to the data in Table 5, the normalized matrix is obtained by using Eq. (4). In order to obtain the weighted normalized matrix, Eq. (6) is used. For each alternative, $P_{j}, R_{j}, Q_{j}$ and degree of efficiency $\left(N_{j}\right)$ values are calculated according to Eqs. (8), (9), (11) and (12). Rank of alternatives is obtained according to the $N_{j}$ values of alternatives and presented with $S_{j}$. 
According to the ranking of the performance measures with COPRAS-G shown in Table 6, the best performance measure is selected as Number of Unplanned Maintenance (Equipment Failures). If the indexes are calculated for the pessimistic $\left(\mathrm{w}_{\mathrm{i}}\right)$ and optimistic values $\left(b_{i}\right)$ in Table 6 , the results are obtained as in Table 7 . As it can be seen in Table 7, ranking of performance measures is changed according to the pessimistic approach, but the ranking of performance measures according to optimistic approach and interval values is the same.

Table 6. Solution results

\begin{tabular}{|c|c|c|c|c|c|}
\hline \multirow[t]{2}{*}{ Performance measures } & \multicolumn{3}{|r|}{$\begin{array}{l}\text { Alternative's } \\
\text { weight }\end{array}$} & $\begin{array}{c}\text { Alternative's } \\
\text { degree of } \\
\text { efficiency }\end{array}$ & Rank \\
\hline & $P_{j}$ & $R_{j}$ & $Q_{j}$ & $N_{j}$ & $S_{j}$ \\
\hline Environmental, health \& safety problems & 0.0853 & 0.0147 & 0.0946 & 87.2397 & 8 \\
\hline Organization problems \& labour unrest & 0.0753 & 0.0094 & 0.0899 & 82.9506 & 10 \\
\hline Human factor & 0.0868 & 0.0098 & 0.1008 & 92.9651 & 6 \\
\hline Availability of maintenance personnel & 0.0792 & 0.0100 & 0.0928 & 85.6426 & 9 \\
\hline Quality losses & 0.0918 & 0.0147 & 0.1011 & 93.2615 & 5 \\
\hline Reduced speed & 0.0928 & 0.0143 & 0.1024 & 94.4744 & 4 \\
\hline MTBF & 0.0842 & 0.0113 & 0.0964 & 88.8848 & 7 \\
\hline MTTR & 0.0924 & 0.0091 & 0.1075 & 99.1354 & 2 \\
\hline Number of unplanned maintenance & 0.0962 & 0.0113 & 0.1084 & 100.0000 & 1 \\
\hline Reduced yield & 0.0967 & 0.0147 & 0.1060 & 97.7755 & 3 \\
\hline
\end{tabular}

Table 7. Solution results for pessimistic, optimistic and interval values of initial decision matrix

\begin{tabular}{lcccccc}
\hline \multirow{2}{*}{ Performance measures } & \multicolumn{2}{c}{ Alternatives degree of efficiency $N_{j}$} & \multicolumn{2}{c}{ Rank $S_{j}$} \\
\cline { 2 - 7 } & Pess. & Opt. & Int. & Pess. & Opt. & Int. \\
\hline Environmental, health \& safety problems & 76.0482 & 81.0706 & 87.2397 & 10 & 8 & 8 \\
\hline Organization problems \& labour unrest & 88.3336 & 91.9360 & 82.9506 & 4 & 10 & 10 \\
\hline Human factor & 92.3609 & 91.2876 & 92.9651 & 3 & 6 & 6 \\
\hline Availability of maintenance personnel & 85.4656 & 95.9997 & 85.6426 & 6 & 9 & 9 \\
\hline Quality losses & 77.6093 & 83.4960 & 93.2615 & 9 & 5 & 5 \\
\hline Reduced speed & 84.3866 & 84.1348 & 94.4744 & 8 & 4 & 4 \\
\hline MTBF & 86.2096 & 87.7309 & 88.8848 & 5 & 7 & 7 \\
\hline MTTR & 100.0000 & 100.0000 & 99.1354 & 1 & 2 & 2 \\
\hline Number of unplanned maintenance & 93.0913 & 94.4623 & 100.0000 & 2 & 1 & 1 \\
\hline Reduced yield & 85.0679 & 85.5509 & 97.7755 & 7 & 3 & 3 \\
\hline
\end{tabular}




\section{Proposed fuzzy COPRAS method for the evaluation of new performance measures in TPM}

In this study, fuzzy COPRAS method is developed in eight steps for evaluation of new performance measures in TPM. The aim of this study is to assess performance measures in TPM considering multiple and conflicting criteria under incomplete and vague information using the fuzzy set theory.

In the Step 1, we construct the fuzzy decision matrix as shown in Table 8:

Table 8. Fuzzy decision matrix

\begin{tabular}{|c|c|c|c|c|c|c|c|c|c|}
\hline \multirow{2}{*}{ Performance measures } & \multicolumn{3}{|c|}{$\otimes x_{1}$} & \multicolumn{3}{|c|}{$\otimes x_{2}$} & \multicolumn{3}{|c|}{$\otimes x_{3}$} \\
\hline & $a_{1}$ & $b_{1}$ & $c_{1}$ & $a_{2}$ & $b_{2}$ & $c_{2}$ & $a_{3}$ & $b_{3}$ & $c_{3}$ \\
\hline Environmental, health \& safety problems & 50 & 62.5 & 75 & 75 & 80 & 85 & 70 & 75 & 80 \\
\hline Organization problems \& labour unrest & 55 & 67.5 & 80 & 52 & 54 & 56 & 62 & 69 & 76 \\
\hline Human factor & 60 & 69 & 78 & 75 & 80 & 85 & 70 & 75 & 80 \\
\hline Availability of maintenance personnel & 70 & 81.5 & 93 & 54 & 58 & 62 & 55 & 63.5 & 72 \\
\hline Quality losses & 84 & 86.5 & 89 & 80 & 85 & 90 & 75 & 77.5 & 80 \\
\hline Reduced speed & 84 & 86.5 & 89 & 75 & 80 & 85 & 70 & 75 & 80 \\
\hline MTBF & 85 & 90 & 95 & 78 & 83 & 88 & 60 & 65 & 70 \\
\hline MTTR & 85 & 90 & 95 & 78 & 83 & 88 & 70 & 75 & 80 \\
\hline Number of unplanned maintenance & 80 & 87.5 & 95 & 80 & 85 & 90 & 80 & 82.5 & 85 \\
\hline Reduced yield & 84 & 86.5 & 89 & 80 & 85 & 90 & 85 & 87.5 & 90 \\
\hline \multirow{2}{*}{ Performance measures } & \multicolumn{3}{|c|}{$\otimes x_{4}$} & \multicolumn{3}{|c|}{$\otimes x_{5}$} & \multicolumn{3}{|c|}{$\otimes x_{6}$} \\
\hline & $a_{4}$ & $b_{4}$ & $c_{4}$ & $a_{5}$ & $b_{5}$ & $c_{5}$ & $a_{6}$ & $b_{6}$ & $c_{6}$ \\
\hline Environmental, health \& safety problems & 75 & 77.5 & 80 & 65 & 70 & 85 & 80 & 85 & 90 \\
\hline Organization problems \& labour unrest & 70 & 72.5 & 75 & 57 & 69 & 81 & 52 & 54 & 56 \\
\hline Human factor & 70 & 75 & 80 & 70 & 74 & 78 & 55 & 56.5 & 58 \\
\hline Availability of maintenance personnel & 80 & 85 & 90 & 59 & 76 & 93 & 54 & 58 & 62 \\
\hline Quality losses & 75 & 80 & 85 & 63 & 76 & 89 & 80 & 85 & 90 \\
\hline Reduced speed & 85 & 90 & 95 & 80 & 82.5 & 85 & 80 & 82.5 & 85 \\
\hline MTBF & 70 & 72.5 & 75 & 80 & 82.5 & 85 & 60 & 65 & 70 \\
\hline MTTR & 80 & 85 & 90 & 80 & 84 & 88 & 50 & 52.5 & 55 \\
\hline Number of unplanned maintenance & 80 & 85 & 90 & 85 & 87.5 & 90 & 60 & 65 & 70 \\
\hline Reduced yield & 75 & 80 & 85 & 85 & 87.5 & 90 & 80 & 85 & 90 \\
\hline
\end{tabular}


In step 2, the fuzzy decision matrix is normalized. The linear scale transformation is carried out to change the various criteria scales into a comparable scale. The normalization method is to preserve the property that the ranges of normalized triangular fuzzy numbers belong to $[0 ; 1]$.

In step 3, we calculate the fuzzy weighted normalized decision matrix.

In step 4 , we calculate the sums of the fuzzy $\tilde{P}_{j}$ criterion values whose larger values are more preferable.

In step 5 , we calculate the sums of the fuzzy $\tilde{R}_{j}$ criterion values whose smaller values are more preferable.

In step 6, we calculate the relative significance of each alternative, $\tilde{Q}_{j}$. The fuzzy $\tilde{P}_{j}$, $\tilde{R}_{j}, \tilde{Q}_{j}$ and $\tilde{N}_{j}$ values are calculated by the formulas given above as Eqs. (7), (8), (10) and (12), respectively. When these values are calculated, all fuzzy judgments are not converted to real numbers and all calculations are performed in accordance with the fuzzy arithmetic. The values of fuzzy $\tilde{P}_{j}$ criterion, fuzzy $\tilde{R}_{j}$ criterion, fuzzy $\tilde{Q}_{j}$ criterion and fuzzy $\tilde{N}_{j}$ criterion are given in Table 9 . The membership functions of fuzzy $\tilde{Q}_{j}$ criterion are shown in Figure 5.

Table 9. Fuzzy $\tilde{P}_{j}, \tilde{R}_{j}, \tilde{Q}_{j}$ and $\tilde{N}_{j}$ values

\begin{tabular}{lccccccccccccccc}
\hline $\begin{array}{l}\text { Performance } \\
\text { Measures }\end{array}$ & \multicolumn{1}{c}{$\tilde{P}_{j}$} & \multicolumn{1}{c}{$\tilde{R}_{j}$} & \multicolumn{1}{c}{$\tilde{Q}_{j}$} \\
\hline $\begin{array}{l}\text { Environmental, } \\
\text { health \& safety } \\
\text { problems }\end{array}$ & 0.427 & 0.470 & 0.516 & 0.033 & 0.035 & 0.037 & 0.474 & 0.526 & 0.582 & 74.230 & 86.730 & 101.140 \\
\hline $\begin{array}{l}\text { Organization } \\
\text { problems \& } \\
\text { labour unrest }\end{array}$ & 0.384 & 0.429 & 0.473 & 0.053 & 0.055 & 0.057 & 0.415 & 0.464 & 0.514 & 64.920 & 76.530 & 89.370 \\
\hline $\begin{array}{l}\text { Human factor } \\
\text { Availability of } \\
\text { maintenance } \\
\text { personnel }\end{array}$ & 0.441 & 0.480 & 0.520 & 0.051 & 0.053 & 0.054 & 0.473 & 0.517 & 0.562 & 74.000 & 85.280 & 97.720 \\
\hline $\begin{array}{l}\text { Quality losses } \\
\text { Reduced speed }\end{array}$ & 0.505 & 0.530 & 0.556 & 0.535 & 0.562 & 0.035 & 0.036 & 0.037 & 0.555 & 0.589 & 0.624 & 86.820 & 97.120 & 108.510 \\
\hline MTBF & 0.476 & 0.505 & 0.533 & 0.043 & 0.046 & 0.050 & 0.512 & 0.547 & 0.584 & 80.060 & 90.260 & 101.590 \\
\hline MTTR & 0.507 & 0.539 & 0.571 & 0.054 & 0.057 & 0.060 & 0.536 & 0.573 & 0.611 & 83.910 & 94.560 & 106.290 \\
\hline $\begin{array}{l}\text { Number of } \\
\text { unplanned } \\
\text { maintenance }\end{array}$ & 0.519 & 0.551 & 0.583 & 0.043 & 0.046 & 0.050 & 0.554 & 0.593 & 0.634 & 86.670 & 97.840 & 110.220 \\
\hline Reduced yield & 0.528 & 0.551 & 0.573 & 0.033 & 0.035 & 0.037 & 0.575 & 0.606 & 0.639 & 89.970 & 100.000 & 111.150 \\
\hline
\end{tabular}




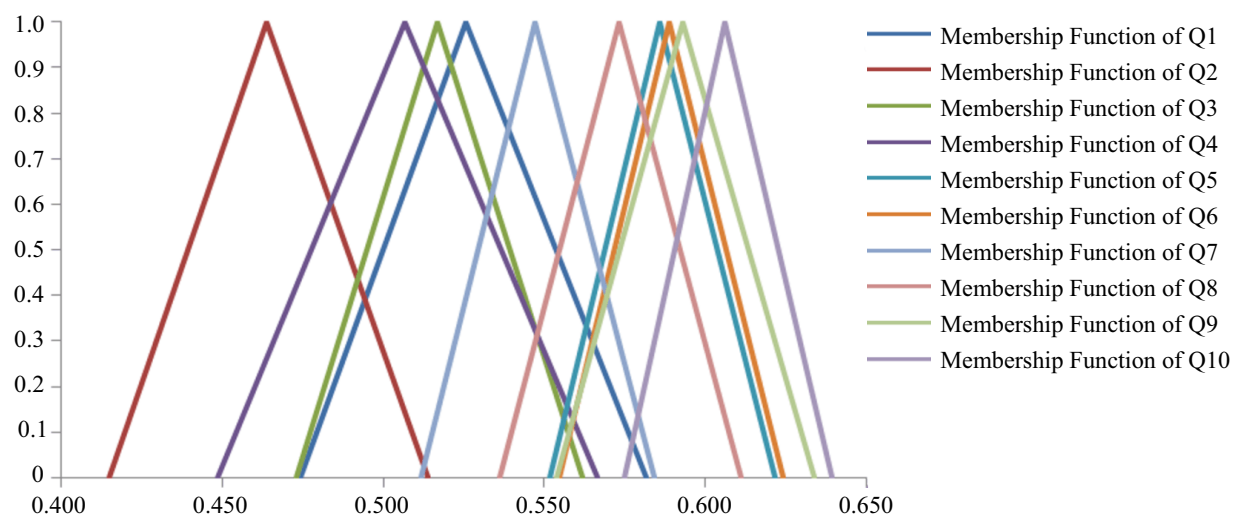

Fig. 5. The membership functions of fuzzy $\tilde{Q}_{j}$ criterion

In Step 7, we determine the optimally criterion, K. To determine the optimally criterion $\mathrm{K}$, it is used one of the fuzzy ranking method based on $\alpha$-cuts (Basirzadeh, Abbasi 2008). According to this method, if $\tilde{A}=\left(x_{0}, \delta, \beta\right)$ is a triangular fuzzy number, the parametric values assigned to the fuzzy numbers, represented by $Q^{\operatorname{Tr} i}(\tilde{A})$ calculated as follows:

$$
Q^{\operatorname{Tr} i}(\tilde{A})=2 x_{0}(1-\alpha)+\frac{(\beta-\delta)}{2}(1-\alpha)^{2} .
$$

The fuzzy $\tilde{Q}_{j}$ criterion values of performance measures are ranked using the above equation and the rankings of the alternatives according to different $\alpha$-cut levels are given in Table 10. According to Table 10, the best three performance measures for the all level of $\alpha$-cut are performance measure "reduced yield", performance measure "number of unplanned maintenance (equipment failures)" and performance measure "reduced speed". The other performance measures have different rankings for the different levels of $\alpha$-cuts. According to this Table, the optimally criterion K is TFN (0.5749, $0.6061,0.6391)$.

In Step 8 , we calculate the utility degree of each alternative and the fuzzy $\tilde{N}_{j}$ values.

Table 10 . The ranking of fuzzy $\tilde{Q}_{j}$ criterion values of performance measures

\begin{tabular}{cc}
\hline$\alpha$ & Ranking of fuzzy numbers according to values of $Q^{\text {Tri }}\left(\tilde{Q}_{j}\right)$ \\
\hline 0.1 & $\tilde{Q}_{10}>\tilde{Q}_{9}>\tilde{Q}_{6}>\tilde{Q}_{5}>\tilde{Q}_{8}>\tilde{Q}_{7}>\tilde{Q}_{1}>\tilde{Q}_{3}>\tilde{Q}_{4}>\tilde{Q}_{2}$ \\
0.2 & $\tilde{Q}_{10}>\tilde{Q}_{9}>\tilde{Q}_{6}>\tilde{Q}_{5}>\tilde{Q}_{8}>\tilde{Q}_{7}>\tilde{Q}_{1}>\tilde{Q}_{3}>\tilde{Q}_{4}>\tilde{Q}_{2}$ \\
0.3 & $\tilde{Q}_{10}>\tilde{Q}_{9}>\tilde{Q}_{6}>\tilde{Q}_{5}>\tilde{Q}_{8}>\tilde{Q}_{7}>\tilde{Q}_{1}>\tilde{Q}_{3}>\tilde{Q}_{4}>\tilde{Q}_{2}$ \\
0.4 & $\tilde{Q}_{10}>\tilde{Q}_{6}>\tilde{Q}_{9}>\tilde{Q}_{5}>\tilde{Q}_{8}>\tilde{Q}_{7}>\tilde{Q}_{1}>\tilde{Q}_{3}>\tilde{Q}_{4}>\tilde{Q}_{2}$ \\
0.5 & $\tilde{Q}_{10}>\tilde{Q}_{6}>\tilde{Q}_{9}>\tilde{Q}_{5}>\tilde{Q}_{8}>\tilde{Q}_{7}>\tilde{Q}_{1}>\tilde{Q}_{3}>\tilde{Q}_{4}>\tilde{Q}_{2}$ \\
0.6 & $\tilde{Q}_{10}>\tilde{Q}_{6}>\tilde{Q}_{9}>\tilde{Q}_{5}>\tilde{Q}_{8}>\tilde{Q}_{7}>\tilde{Q}_{1}>\tilde{Q}_{3}>\tilde{Q}_{4}>\tilde{Q}_{2}$ \\
0.7 & $\tilde{Q}_{10}>\tilde{Q}_{6}>\tilde{Q}_{9}>\tilde{Q}_{5}>\tilde{Q}_{8}>\tilde{Q}_{7}>\tilde{Q}_{1}>\tilde{Q}_{3}>\tilde{Q}_{4}>\tilde{Q}_{2}$ \\
0.8 & $\tilde{Q}_{10}>\tilde{Q}_{6}>\tilde{Q}_{9}>\tilde{Q}_{5}>\tilde{Q}_{8}>\tilde{Q}_{7}>\tilde{Q}_{1}>\tilde{Q}_{3}>\tilde{Q}_{4}>\tilde{Q}_{2}$ \\
0.9 & $\tilde{Q}_{10}>\tilde{Q}_{6}>\tilde{Q}_{9}>\tilde{Q}_{5}>\tilde{Q}_{8}>\tilde{Q}_{7}>\tilde{Q}_{1}>\tilde{Q}_{3}>\tilde{Q}_{4}>\tilde{Q}_{2}$ \\
\hline
\end{tabular}




\section{Research results and discussion}

We used Taguchi design methodology in order to reduce the number of designs. The conjoint analysis was performed by using Taguchi OA 16 table. The ANOVA results of conjoint analysis showed that the proposed multiple regression model for the twelve performance measures impact on TPM is statistically significant. In the following, we present a comparative analysis for pessimistic and optimistic COPRAS methods and COPRAS-G and fuzzy COPRAS methods.

Figure 6 shows the comparisons among the methods pessimistic COPRAS, optimistic COPRAS, COPRAS-G and proposed fuzzy COPRAS according to the rankings of the performance measures. In Figure 6, according to the optimistic values, the best performance measure is number of unplanned maintenance (equipment failures); according to the pessimistic values, the best performance measure is MTTR; according to the grey values (COPRAS-G) of performance measures, the best performance measure is also number of unplanned maintenance (equipment failures); according to the fuzzy values (proposed fuzzy COPRAS), also the best performance measure is reduced yield. The last ranked performance measure in the rankings is organization problems \& labour unrest with respect to optimistic, grey and fuzzy COPRAS methods. Organization problems \& labour unrest is the 4th ranked performance measure with respect to pessimistic COPRAS method.

Proposed fuzzy COPRAS method is preferred over the COPRAS-G method since it is not using the conversion method which does not guarantee one-to-one correspondence between fuzzy numbers and real numbers. In the proposed fuzzy COPRAS method, all fuzzy judgments are not converted to real numbers and all calculations are performed in accordance with the fuzzy arithmetic. Thus, it can be said that in this method the information loss is not included. It is seen that proposed fuzzy COPRAS method gives similar but not the same results of other COPRAS methods.

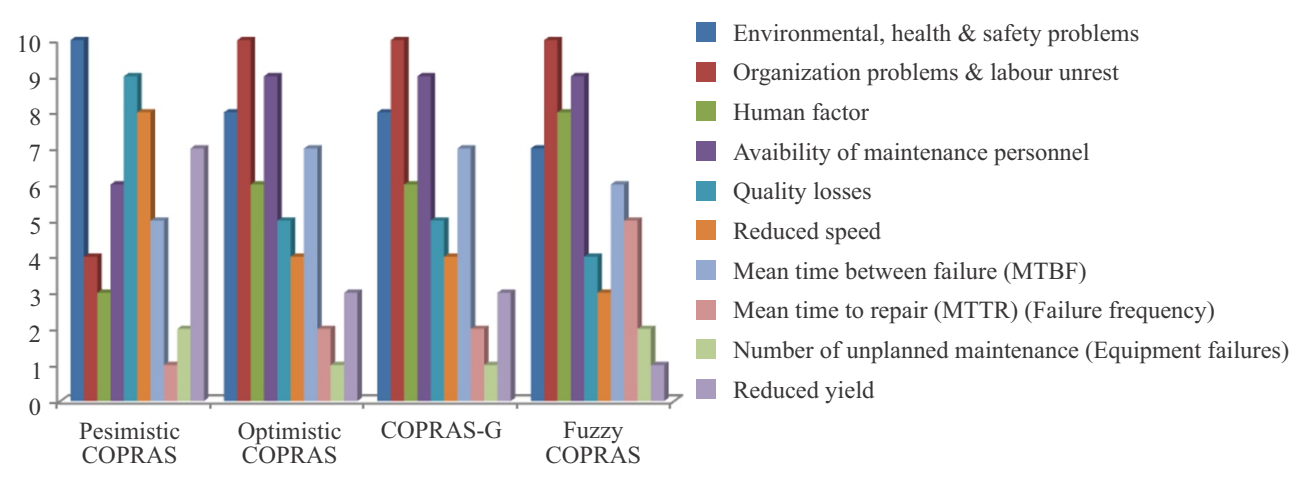

Fig. 6. The comparison of proposed Fuzzy COPRAS and other COPRAS methods 


\section{Conclusions}

In today's competitive environment, TPM has been widely implemented as a lean production tool for improving manufacturing performance in many organizations. The effectiveness of TPM should be measured by some factors since it can make a great contribution to companies in advancing their manufacturing operations. In most organization, the effectiveness of TPM is measured by only OEE metric. Thereby, in this study, primarily new performance measures having impact on successfully TPM implementation are developed according to literature review and practical aspect including interviews of employees worked at TPM department in different manufacturing companies. Then a fuzzy MCDM model is employed based upon COPRAS method for the evaluation of these performance measures in TPM. Finally a comparison between the proposed fuzzy COPRAS and conventional COPRAS methods is presented. The results of comparison illustrate that the proposed Fuzzy COPRAS method finds almost the same ranks others COPRAS methods.

In this study, it is developed new performance measures oriented towards the quantification of TPM implementation effectiveness and evaluated the new performance measure in TPM under fuzzy environment. In the evaluation process, COPRAS-G is applied for evaluation of new performance measures in TPM. Then the fuzzy COPRAS method is developed for the evaluation of new performance measures in TPM. When developing the fuzzy COPRAS all calculations are made based on the fuzzy arithmetic and fuzzy ranking operations. Therefore, no fuzzy value is converted to a crisp value.

This study helps to operators and executives to visualize the results of the investments made in TPM efforts with newly developed performance measures of TPM. The limitation of the proposed ordinary fuzzy COPRAS is its need for a modification in case of new extensions of fuzzy sets. In the future research, the proposed performance measures are going to be tested in a real-world manufacturing company where the original OEE has been evaluated previously. Proposed fuzzy COPRAS method can also be extended using intuitionistic, hesitant fuzzy sets or neutrosophic sets to evaluate newly developed performance measures in TPM.

\section{References}

Aghdaie, M. H.; Hashemkhani Zolfani, S.; Zavadskas, E. K. 2013. Decision making in machine tool selection: an integrated approach with SWARA and COPRAS-G methods, Inzinerine Ekonomika - Engineering Economics 24(1): 5-17.

Akhavan, P.; Barak, S.; Maghsoudlou, H.; Antucheviciene, J. 2015. FQSPM-SWOT for strategic alliance planning and partner selection; case study in a holding car manufacturer company, Technological and Economic Development of Economy 21(2): 165-185.

http://dx.doi.org/10.3846/20294913.2014.965240

Andersson, R.; Manfredsson, P.; Lantz, B. 2015. Total productive maintenance in support processes: an enabler for operation excellence, Total Quality Management \& Business Excellence 26(9-10): 1042-1055. http://dx.doi.org/10.1080/14783363.2015.1068598

Antucheviciene, J.; Zavadskas, E. K.; Zakarevicius, A. 2012. Ranking redevelopment decisions of derelict buildings and analysis of ranking results, Economic Computation and Economic Cybernetics Studies and Research 46(2): 37-62. 
Attri, R.; Grovera, S.; Deva, N. 2014. A graph theoretic approach to evaluate the intensity of barriers in the implementation of total productive maintenance (TPM), International Journal of Production Research 52(10): 3032-3051. http://dx.doi.org/10.1080/00207543.2013.860250

Basirzadeh, H.; Abbasi, R. 2008. A new approach for ranking fuzzy numbers based on $\alpha$-cuts, Journal of Applied Mathematics \& Informatics 26(3-4): 767-778.

Bausys, R.; Zavadskas, E. K.; Kaklauskas, A. 2015. Application of neutrosophic set to multicriteria decision making by COPRAS, Economic Computation and Economic Cybernetics Studies and Research 49(2): 84-98.

Bitarafan, M.; Hashemkhani Zolfani, S.; Arefi, S. L.; Zavadskas, E. K. 2012. Evaluating the construction methods of cold-formed steel structures in reconstructing the areas damaged in natural crises using the methods AHP and COPRAS-G, Archives of Civil and Mechanical Engineering 12(3): 360-367. http://dx.doi.org/10.1016/j.acme.2012.06.015

Braglia, M.; Frosolini, M.; Zammori, F. 2009. Overall equipment effectiveness of a manufacturing line (OEEML), Journal of Manufacturing Technology Management 20(1): 8-29.

http://dx.doi.org/10.1108/17410380910925389

Chatterjee, N. C.; Bose, K. B. 2012. A COPRAS-F base multi-criteria group decision making approach for site selection of wind farm, Decision Science Letters 2: 1-10.

http://dx.doi.org/10.5267/j.dsl.2012.11.001

Chatterjee, P.; Chakraborty, S. 2012. Material selection using preferential ranking methods, $\mathrm{Ma}$ terials and Design 35: 384-393. http://dx.doi.org/10.1016/j.matdes.2011.09.027

Chlebus, E.; Helman, J.; Olejarczyk, M.; Rosienkiewicz, M. 2015. A new approach on implementing TPM in a mine - a case study, Archives of Civil and Mechanical Engineering 15(4): 873-884. http://dx.doi.org/10.1016/j.acme.2015.07.002

Dal, B.; Tugwell, P.; Greatbanks, R. 2000. Overall equipment effectiveness as a measure for operational improvement: a practical analysis, International Journal of Operations \& Production Management 20(13): 1488-1502. http://dx.doi.org/10.1108/01443570010355750

Davis, R. 1996. Making TPM a part of factory life, Works Management 49(7): 16-27.

Ecer, F. 2015. Performance evaluation of internet banking branches via a hybrid MCDM model under fuzzy environment, Economic Computation and Economic Cybernetics Studies and Research 49(2): 211-229.

Ghorabaee, M. K.; Amiri, M.; Sadaghiani, J. S.; Goodarzi, G. H. 2014. Multiple criteria group decision-making for supplier selection based on COPRAS method with interval type-2 fuzzy sets, International Journal of Advanced Manufacturing Technology 75: 1115-1130.

http://dx.doi.org/10.1007/s00170-014-6142-7

Gitinavard, H.; Mousavi, S. M.; Vahdani, B. 2016. Soft computing-based new interval-valued hesitant fuzzy multi-criteria group assessment method with last aggregation to industrial decision problems, Methodologies and Application-Soft Computing 1-19.

http://dx.doi.org/10.1007/s00500-015-2006-9

Hansen, R. C. 2002. Overall equipment effectiveness: a powerful production/maintenance tool for increased profits. New York: Industrial Press Inc.

Hashemkhani Zolfani, S.; Chen, I. S.; Rezaeiniya, N.; Tamosaitiene, J. 2012. A hybrid MCDM model encompassing AHP and COPRAS-G methods for selecting company supplier in Iran, Technological and Economic Development of Economy 18(3): 529-543.

http://dx.doi.org/10.3846/20294913.2012.709472

Huang, S. H.; Dismukes, J. P.; Shi, J.; Razzak, M. A.; Bodhale, R.; Robinson, D. E. 2003. Manufacturing productivity improvement using effectiveness metrics and simulation analysis, International Journal of Production Research 41(3): 513-527. http://dx.doi.org/10.1080/0020754021000042391 
Jeon, J.; Kim, C.; Lee, H. 2011. Measuring efficiency of total productive maintenance (TPM): a three-stage data envelopment analysis (DEA) approach, Total Quality Management \& Business Excellence 22(8): 911-924. http://dx.doi.org/10.1080/14783363.2011.593865

Kahraman, C.; Onar, S. C.; Oztaysi, B. 2015. Fuzzy multicriteria decision-making: a literature review, International Journal of Computational intelligence Systems 8(4): 637-666.

Liou, J. J. H.; Tamošaitiene, J.; Zavadskas, E. K.; Tzeng, G. H. 2016. New hybrid COPRAS-G MADM model for improving and selecting suppliers in green supply chain management, International Journal of Production Research 54(1): 114-134.

http://dx.doi.org/10.1080/00207543.2015.1010747

Liu, P. D.; Teng, F. 2014. An extended TODIM method for multiple attribute group decisionmaking based on 2-dimension uncertain linguistic variable, Complexity 21(5): 20-30. http://dx.doi.org/10.1002/cplx.21625

Liu, P. D.; Teng, F. 2015. An extended TODIM method for multiple attribute group decisionmaking based on intuitionistic uncertain linguistic variables, Journal of Intelligent \& Fuzzy Systems 29: 701-711. http://dx.doi.org/10.3233/IFS-141441

Liu, P. D.; Wu, X. Y. 2012. A competency evaluation method of human resources managers based on multi-granularity linguistic variables and VIKOR method, Technological and Economic Development of Economy 18(4): 696-710. http://dx.doi.org/10.3846/20294913.2012.753169

Liu, P.; Zhang, X. 2013. Research on the supplier selection of a supply chain based on entropy weight and improved ELECTRE-III method, International Journal of Production Research 49(3): 637-646. http://dx.doi.org/10.1080/00207540903490171

Maity, S. K.; Chatterjee, P.; Chakraborty, S. 2012. Cutting tool material selection using grey complex proportional assessment method, Materials and Design 36: 372-378.

http://dx.doi.org/10.1016/j.matdes.2011.11.044

Mardani, A.; Jusoh, A.; Nor, K. M. D.; Khalifah, Z.; Zakwan, N.; Valipour, A. 2015. Multiple criteria decision-making techniques and their applications - a review of the literature from 2000 to 2014, Economic Research-Ekonomska Istraživanja 28(1): 516-571.

http://dx.doi.org/10.1080/1331677X.2015.1075139

Mazumdar, A.; Datta, S.; Mahapatra, S. S. 2010. Multicriteria decision-making models for the evaluation and appraisal of teachers' performance, International Journal of Productivity and Quality Management 6(2): 213-230. http://dx.doi.org/10.1504/IJPQM.2010.034406

Muchiri, P.; Pintelon, L. 2008. Performance measurement using overall equipment effectiveness (OEE): literature review and practical application discussion, International Journal of Production Research 46(13): 3517-3535. http://dx.doi.org/10.1080/00207540601142645

Nakajima, S. 1988. Introduction to TPM: total productive maintenance. Cambridge, MA: Productivity Press.

Nguyen, H.-T.; Dawal, S. Z. M.; Nukman, Y.; Aoyama, H. 2014. A hybrid approach for fuzzy multi-attribute decision making in machine tool selection with consideration of the interactions of attributes, Expert Systems with Applications 41(6): 3078-3090.

http://dx.doi.org/10.1016/j.eswa.2013.10.039

Nguyen, H.-T.; Dawal, S. Z. M.; Nukman, Y.; Aoyama, H.; Case, K. 2015. An integrated approach of fuzzy linguistic preference based AHP and fuzzy COPRAS for machine tool evaluation, PLoS ONE 10(9): e0133599. http://dx.doi.org/10.1371/journal.pone.0133599

Oechsner, R.; Pfeffer, M.; Pfitzner, L.; Binder, H.; Muller, E.; Vonderstrass, T. 2003. From overall equipment effectiveness to overall fab effectiveness (OFE), Materials Science in Semiconductor Processing 5: 333-339. http://dx.doi.org/10.1016/S1369-8001(03)00011-8

Parida, A.; Chattopadhyay, G.; Kumar, U. 2005. Multi criteria maintenance performance measurement: a conceptual model, in Proceedings of the 18th International Congress of COMADEM, 31 August - 2 September 2005, Cranfield, UK, 349-356. 
Piehnicki, A. S.; Herrero Sola, A. V.; Trojan, F. 2015. Decision-making towards achieving worldclass total productive maintenance, International Journal of Operations \& Production Management 15(4): 873-884.

Razavi Hajiagha, S. H.; Hashemi, S. S.; Zavadskas, E. K. 2013. A complex proportional assessment method for group decision making in an interval-valued intuitionistic fuzzy environment, Technological and Economic Development of Economy 19(1): 22-37.

http://dx.doi.org/10.3846/20294913.2012.762953

Rezaeiniya, N.; Hashemkhani Zolfani, S.; Zavadskas, E. K. 2012. Greenhouse locating based on ANP-COPRAS-G methods - an empirical study based on Iran, International Journal of Strategic Property Management 16(2): 188-200. http://dx.doi.org/10.3846/1648715X.2012.686459

Rodrigues, K.; Hatakeyama, K. 2006. Analysis of the fall of TPM in companies, Journal of Materials Processing Technology 179: 276-279. http://dx.doi.org/10.1016/j.jmatprotec.2006.03.102

Scott, D.; Pisa, R. 1998. Can overall factory effectiveness prolong Moore's Law?, Solid State Technology 41: 82 .

Tamošaitiene, J.; Gaudutis, E. 2013. Complex assessment of structural systems used for high-rise buildings, Journal of Civil Engineering and Management 19(2): 305-317.

http://dx.doi.org/10.3846/13923730.2013.772071

Tavana, M.; Momeni, E.; Rezaeiniya, N.; Mirhedayatian, S. M.; Rezaeiniya, H. 2013. A novel hybrid social media platform selection model using fuzzy ANP and COPRAS-G, Expert Systems with Applications 40(14): 5694-5702. http://dx.doi.org/10.1016/j.eswa.2013.05.015

Yazdani, M.; Alidoosti, A.; Zavadskas, E. K. 2011. Risk analysis of critical infrastructures using fuzzy COPRAS, Economic Research-Ekonomska Istraživanja 24(4): 27-40.

http://dx.doi.org/10.1080/1331677X.2011.11517478

Zavadskas, E. K.; Antucheviciene, J. 2007. Multiple criteria evaluation of rural building's regeneration alternatives, Building and Environment 42(1): 436-451.

http://dx.doi.org/10.1016/j.buildenv.2005.08.001

Zavadskas, E. K.; Kaklauskas, A.; Turskis, Z.; Tamošaitiene, J. 2008a. Selection of the effective dwelling house walls by applying attributes values determined at intervals, Journal of Civil Engineering and Management: International Research and Achievements 14(2): 85-93.

http://dx.doi.org/10.3846/20294913.2014.892037

Zavadskas, E. K.; Kaklauskas, A.; Turskis, Z.; Tamošaitiene, J. 2009. Multi-attribute decisionmaking model by applying grey numbers, Informatica 20(2): 305-320.

Zavadskas, E. K.; Turskis, Z.; Kildiene, S.; 2014. State of art surveys of overviews on MCDM/ MADM methods, Technological and Economic Development of Economy 20(1): 165-179.

http://dx.doi.org/10.3846/20294913.2014.892037

Zavadskas, E. K.; Turskis, Z.; Tamošaitienè, J.; Marina, V. 2008b. Multicriteria selection of project managers by applying grey criteria, Technological and Economic Development of Economy 14(4): 462-477. http://dx.doi.org/10.3846/1392-8619.2008.14.462-477

Zavadskas, E. K.; Turskis, Z.; Tamosaitiene, J. 2010. Risk assessment of construction projects, Journal of Civil Engineering and Management 16(1): 33-46.

http://dx.doi.org/10.3846/jcem.2010.03

Zhang, X.; Jin, F.; Liu, P. D. 2013. A grey relational projection method of multi-attribute decision making based on intuitionistic trapezoidal fuzzy number, Applied Mathematical Modelling 37(5): 3467-3477. http://dx.doi.org/10.1016/j.apm.2012.08.012 
Ebru TURANOGLU BEKAR is currently a PhD student at the Graduate School of Natural and Applied Sciences of Dokuz Eylul University in Izmir. Her specific research interests are in the areas of Artificial Neural Network, Engineering Statistics, Forecasting, Fuzzy Sets Theory, Mathematical Programming, Multi-Criteria Decision Making, and Statistical Quality Control. Ebru TURANOGLU BEKAR attended her PhD degree in Industrial Engineering at Dokuz Eylul University; her MSc degree in Industrial Engineering at Istanbul Technical and Selcuk University, Turkey in 2012, and her BSc in Industrial Engineering at Selcuk University, Turkey in 2009.

Mehmet CAKMAKCI, Associate Professor, has been a faculty member at Dokuz Eylul University, Department of Industrial Engineering since 2002. His specific research interests are in the areas of Management and Organization, Project Management, Quality Management, Strategic Management and Operations Management. Dr Mehmet CAKMAKCI completed his PhD degree in Technical Sciences at Technische Üniversitat Wien, Austria in 1990; and his BSc in Mechanical Engineering at Istanbul Technical University, Turkey in 1982.

Cengiz KAHRAMAN is a full Professor at Istanbul Technical University. His research areas are engineering economics, quality control and management, statsitical decision making, multicriteria decision making, and fuzzy decision making. He published about 170 journal papers and about 120 conference papers. He became the guest editors of many international journals and the editor of many international books from Springer and Atlantis Press. He is the member of editorial boards of 20 international journals. He organized various conferences such as FLINS, RACR, FSSCMIE, etc. He was the vice dean of ITU Management Faculty between 2004-2007 and the head of ITU Industrial Engineering Department between 2010-2013. 